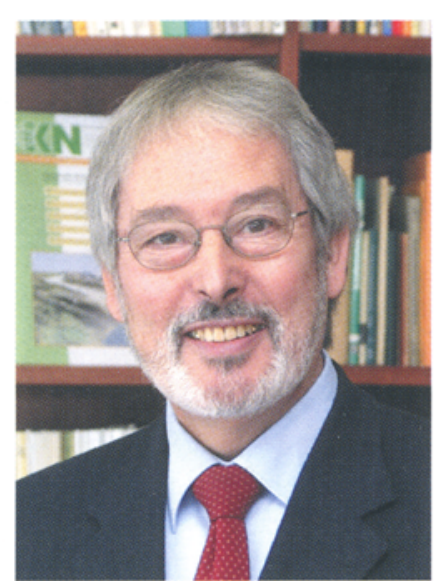

\section{Von Fantasie und Realität}

Liebe Leserin, lieber Leser,

Sie halten das Dezemberheft lhrer KN in Händen und es ist bald Weihnachten. Und noch ein paar Tage weiter neigt sich das Jahr 2004 seinem Ende entgegen, und das neve Jahr 2005 will gebührend empfangen werden. Festliche Tage sind dies, aber auch Tage des Rückschauens, der Ruhe und der Besinnlichkeit. Diese Tage haben ihren eigenen Zauber. Viele von uns erliegen ihm und erinnern sich an ihre Kindheit, und bisweilen kommt es vor, dass wir uns in Fantasiereiche und Märchenwelten entführen lassen.

Spätestens jetzt fragen Sie: Gehören solche Gedanken in eine seriöse Fachzeitschrift, die sich mit ernsthaften Themen, mit wissenschaftlichen Problemen, mit Berichten aus der fachlichen Alltags- und Arbeitswelt beschäftigt? Schon beim Blick auf unser Titelbild haben Sie, vielleicht kopfschüttelnd, die kartographische Darstellung einer imaginären Landschaft wahrgenommen, in die eine Elfe, Sterne verstreuend, mit Zauberstab hineinschwebt. Und doch sind Sie jetzt mittendrin in einem ernsthaften kartographischen Unternehmen, das die Schülerinnen und Schüler der Fachklasse Kartographie der JohannesGutenberg-Berufsschule in Stuttgart unternommen haben. „Eine Märchenreise" heißt das Projekt, in dem angehende Kartographinnen und Kartographen des dritten Ausbildungsjahres fantasievoll Märchen geschrieben, dazu imaginäre Welten geschaffen und diese kartographisch dargestellt haben. Das faszinierende, 30 Seiten umfassende Werk, das vom Konzept bis zum Druck von Schülerhand stammt, ist mit dem Ersten Preis des „Wettbewerbs Berufliche Schulen der Landesstiftung BadenWürttemberg" ausgezeichnet und mit einem Preisgeld von 15000 Euro honoriert worden. Wir freven uns, dass die Preisträgerinnen und Preisträger in diesem KNHeft über ihre Arbeit berichten und eine Probe davon beilegen. Und als Dankeschön und als eine weitere Anerkennung fanden wir es nur recht, das Titelblatt einer KN-Ausgabe mit einem Ausschnitt aus dem Gemeinschaftswerk zu schmücken.

Natürlich halten wir in diesem Heft auch andere Themen für Sie bereit. Eines davon widmet sich einem Problem, das man fast schon als Generationenkonflikt unter Kar- tographen bezeichnen könnte: der Aussagekraft gedruckter und am Bildschirm präsentierter Karten, dem Gestaltungspotenzial und den Nutzungsumgebungen beider medialer Erscheinungsformen der Kartographie. Sabine Hennig geht dieser Beziehungsproblematik nach. János Györffy und István Klinghammer halten seit langem die Zeit für einen Europa-Atlas für gekommen und präsentieren dazu eine Projektion geringster Verzerrungen. Aus Osterreich berichtet Viktor Kaufmann über die quantitative Erfassung der Morphodynamik eines besonders aktiven Blockgletschers in den Hohen Tavern.

Reproduzierbare Forschungsergebnisse, aus Vermessungen hervorgehende Fakten und deren Visualisierung bilden einen Themenkreis in den $\mathrm{KN}$ - Interpretationen und Meinungen, manchmal auch Auseinandersetzungen darüber, einen anderen. So interpretiert Dietrich Diez die aus der EGRichtlinie 96/9 entstandene Rechtslage des Datenbankschutzes amtlicher topographischer Kartenwerke aus der Sicht der behördlichen Kartographie. Im FebruarHeft der KN wird Paul W. Hertin mit der Frage "Datenbankschutz für topographische Landkarten?" die Auffassung der privatwirtschaftlichen Verleger hierzu darstellen. Zur Diskussion hat übrigens auch der Aufsatz von René Pfahlbusch im Heft 5 zur so genannten Kartenverfälschung herausgefordert, einem Thema, das zweifellos eine gewisse Ambivalenz in sich trägt und Historiker, Politiker und Kartographen gleichermaßen zu Stellungnahmen herausfordert. Gerade hier wollen die KN ein sachliches, friedliches und, wenn es nicht anders geht, auch streitbares Forum sein, das für belegbare wissenschaftliche Erkenntnisse wie für Alltagserfahrungen aus der beruflichen Praxis gleichermaßen offen ist.

Zauber, Fantasie und Märchen - Erkenntnisse, Fakten und Meinungen: Mit diesem breiten Spektrum schließen wir den 54. Jahrgang unserer KN ab. Verlag, Druckerei und Redaktion danken Ihnen, liebe Leserinnen und Leser, für Ihr vielfach gezeigtes Interesse und wünschen Ihnen frohe und besinnliche Weihnachtstage und ein gutes, erfolgreiches neues Jahr.

Herzlich, Ihr

\section{Ron bacuch}

